\title{
New Korean reference for birth weight by gestational age and sex: data from the Korean Statistical Information Service (2008-2012)
}

Jung Sub Lim, MD', Se Won Lim, MD', Ju Hyun Ahn, MD', Bong Sub Song, MD', Kye Shik Shim, MD², II Tae Hwang, MD, PhD ${ }^{3}$

${ }^{1}$ Department of Pediatrics, Korea Cancer Center Hospital, Seoul, 2Department of Pediatrics, Kyung Hee University School of Medicine, Seoul, ${ }^{3}$ Department of Pediatrics, Hallym University College of Medicine, Seoul, Korea
Purpose: To construct new Korean reference curves for birth weight by sex and gestational age using contemporary Korean birth weight data and to compare them with the Lubchenco and the 2010 United States (US) intrauterine growth curves. Methods: Data of 2,336,727 newborns by the Korean Statistical Information Service (2008-2012) were used. Smoothed percentile curves were created by the Lambda Mu Sigma method using subsample of singleton. The new Korean reference curves were compared with the Lubchenco and the 2010 US intrauterine growth curves. Results: Reference of the 3rd, 10th, 25th, 50th, 75th, 90th, and 97th percentiles birth weight by gestational age were made using 2,249,804 (male, 1,159,070) singleton newborns with gestational age 23-43 weeks. Separate birth weight curves were constructed for male and female. The Korean reference curves are similar to the 2010 US intrauterine growth curves. However, the cutoff values for small for gestational age $(<10$ th percentile) of the new Korean curves differed from those of the Lubchenco curves for each gestational age. The Lubchenco curves underestimated the percentage of infants who were born small for gestational age.

Conclusion: The new Korean reference curves for birth weight show a different pattern from the Lubchenco curves, which were made from white neonates more than 60 years ago. Further research on short-term and long-term health outcomes of small for gestational age babies based on the new Korean reference data is needed.

Keywords: Birth weight, Gestational age, Growth charts, Small for gestational age infant, Koreans

\section{Introduction}

Small for gestational age (SGA) means a developing fetus in the uterus or an infant is smaller in size than normal babie's adjusted for sex and gestational age (GA). It is commonly defined as a weight below the 10th percentile for the $\mathrm{GA}^{1)}$. SGA must be differentiated from low birth weight due to prematurity and intrauterine growth restriction (IUGR). Low birth weight is defined as an infant with a birth weight less than 2,500 g, regardless of GA at the time of birth. IUGR, also called "pathological SGA", refers to a condition in which a fetus is unable to achieve its genetically determined potential size.

Some infants born SGA, particularly with IUGR, suffer from acute and chronic consequences. They can suffer from perinatal event such as hypoglycemia, gastro-esophageal reflux, and hypothermia in neonatal period ${ }^{2,3)}$ and, short stature without catch-up, premature adrenarche, and obesity in childhood ${ }^{4-7)}$. Furthermore, SGA infants have significantly increased risk of obesity, hypertension, dyslipidemia, insulin resistance, polycystic ovarian syndrome, type 2 diabetes mellitus, and cardiovascular diseases (CVDs) from children to adulthood $^{3,8)}$.

\footnotetext{
Received: 12 September, 2014 Revised: 29 September, 2014

Address for correspondence:

II Tae Hwang, MD, PhD

Department of Pediatrics, Hallym

University Kangdong Sacred

Heart Hospital, Hallym University

College of Medicine, 150 Seongan-

ro, Gangdong-gu, Seoul 134-701,

Korea

Tel: +82-2-2224-2308

Fax: +82-2-482-8334

E-mail: ithwang83@hallym.or.kr
} 
For a proper assessment and management of SGA, up-todate ethnicity specific birth weight (or length) references by GA are needed ${ }^{9)}$. Thus, many countries including United States (US) reported new birth weight or intrauterine growth references by sex and GA as old reference does not fit for contemporary population ${ }^{10-15)}$. The new references and cut offs are useful for identifying children who have the risk of metabolic disease in the future.

The objectives of this study were: (1) to make the sex and GA specific birth weight reference data of Korean population and to develop new birth weight curves; (2) to compare these Korean specific birth weight curves with old but commonly used curves (the Lubchenco curves) and 2010 US intrauterine growth curves; and (3) to estimate the prevalence of SGA using new curves and Lubchenco curves.

\section{Materials and methods}

\section{Study subjects}

This study was performed using population data released by the Korean Statistical Information Service (KOSIS). The Korean National Statistic Office opened the KOSIS in July 2007 after establishing a statistical information database and building an integrated service system. It started under the national information strategy scheme in 2005. The KOSIS currently provides 343 types of statistics from domestic to international statistics produced by 87 organizations in Korea. In addition, KOSIS releases 100 major indicators of Korea, which provides information on current economic, social situations and health indicators, including birth and death rate data ${ }^{16)}$. This study used 5-year (2008-2012) national birth data (a total of 2,336,727 newborns) provided by KOSIS, which are based on the birth registration for birth certificate. In the birth data set, birth place, birth order, twin or triplet, age of mother/father, sex, birth weight, and estimated GA were available. From this data, mean GA, mean birth weight, multiple pregnancy rate, and preterm, and postterm birth rates of Korean population were calculated.

\section{Reference birth weight by GA}

For the new Korean reference for birth weight by GA, we used data of singleton newborns. We made birth weight reference of male and female separately as birth size is different by sex. The GA was determined by rounding off. Thus, GA 36 weeks represents 36 weeks plus 0 to 6 days. We excluded data with missing weight $(\mathrm{n}=5,728)$; unknown sex; GA under 22 weeks $(n=1,244)$, and over 44 weeks $(n=173)$. Multiple births $(n=67,396)$ were also excluded as it is well known to have negative impact on intrauterine growth. We further excluded "extreme outliers". Extreme outliers were defined as values $>2$ times the interquartile range (25th to 75 th percentiles) below the first quartile and above the third quartile for each $\mathrm{GA}^{17)}$.
Thus, final analysis consisted 2,249,804 (male, 1,159,070) singleton newborns with GA between 23-43 weeks. The $3 \mathrm{rd}$, 10 th, 25th, 50th, 75th, 90th, and 97th percentiles for male and female neonates were calculated.

\section{Creation of curves}

The percentile growth curves were created by using the Cole's Lambda Mu Sigma (LMS) method ${ }^{18)}$. The LMS approach provides curves for mean weight and "standard deviation (SD) bands". These curves are not expected values and SDs of birth weight itself, but of a transformed value, a $z$-score. LMS approach initially estimates the three parameters of BOX-Cox transformation of the distribution of the measurement. The $\mathrm{L}$ determines a nonlinear transformation of birth weight, such that its distribution approximates the normal distribution. The $\mathrm{M}$ stands for the mean of that normal distribution, and $\mathrm{S}$ for its SD. The three parameters are constrained to change smoothly as the covariate changes. L, M, and S correspond to the following formulas: $\mathrm{Z}=\left[(\mathrm{X} / \mathrm{M})^{\mathrm{L}}-1\right] / \mathrm{LS}$, where $\mathrm{X}$ indicates the measured value of birth weight; and centile $=M(1+\mathrm{LSZ})^{1 / \mathrm{L}}$, where $\mathrm{Z}$ is the $z$-score that corresponds to a given percentile. $Z$-score is a measure of the distance in SDs of a sample from the mean. To create smoothed percentile charts for the 3rd, 10th, 25th, 50th, 75th, 90th and 97th percentiles, LMSChartMaker Pro 2.324 (Medical Research Council, London, UK) was used. Subsample of whole subjects was used as LMSChartMaker cover less than 100,000 data input.

\section{Definition of SGA and comparison with other curves}

By definition, $10 \%$ of a population should be $<10$ th percentile (SGA), 80\% between the 10th and 90th percentiles (appropriate for GA), and $10 \%>90$ th percentile (large for GA, LGA) ${ }^{1,10}$. We compared our new Korean reference curves for birth weight with new intrauterine growth curves published recently based on US data. We also compared ours with the Lubchenco curves as they are still commonly used in many countries including Korea for defining SGA.

\section{Statistical analysis}

All data were analyzed using SAS 9.2 (SAS Institute Inc., Cary, $\mathrm{NC}$, USA). The data are presented as the mean $\pm \mathrm{SD}$, percentile values for birth weight according to GA by sex. The new Korean reference curves for birth weight were generated by using LMS methods. The LMS parameters for the curves are also presented.

All drawings are made using GraphPad Prism ver. 5 (GraphPad Software Inc., La Jolla, CA, USA). As GA 36 weeks represent 36 weeks +0 day to +6 days in our data, we make reference curve to shift right by 0.5 weeks for comparison with other data. 


\section{Results}

\section{Subjects characteristics}

The characteristics of the study subjects are presented in Table 1 . The number of subjects in this study was 2,336,727 which cover the whole neonates born between 2008 and 2012 in Korea. The fathers' mean age of the entire subjects was $33.5 \pm 4.5$ years (range, 14-75 years) and the mother's mean age was $30.7 \pm 4.0$ years (range, 12-61 years). The mean GA for the entire subjects was $38.7 \pm 1.7$ weeks (range, 16-49 weeks). The mean birth weight was $3,218 \pm 461 \mathrm{~g}$. Female had lower birth weight than male $(3,266 \pm 466 \mathrm{~g}$ vs. $3,168 \pm 451 \mathrm{~g})$. The number of preterm neonates under 37 weeks of GA was 137,441 (5.9\%) and the number of postterm neonates over 42 weeks of GA was 7,481 (0.3\%).

Table 1. The characteristics of study subjects

\begin{tabular}{lccc}
\hline Variable & No. $(\%)$ & Birth weight $(\mathrm{g})$ & $P$-value \\
\hline Total & $2,336,727(100)$ & $3,218 \pm 461$ & \\
Sex & & & \\
Male & $1,199,897(51.3)$ & $3,266 \pm 466$ & \\
Female & $1,131,003(48.4)$ & $3,168 \pm 451$ & $<0.001$ \\
Unknown & 5,827 & & \\
Multiplicity & & & \\
Singleton & $2,249,804(96.3)$ & $3,244 \pm 434$ & \\
Twin & $66,064(2.8)$ & $2,394 \pm 478$ & \\
Triplet+ & 1,071 & $1,751 \pm 507$ & $<0.001$ \\
Unknown & 1,669 & & \\
\hline
\end{tabular}

\section{Percentile distribution of birth weight by sex and GA}

The mean and percentile birth weight of male newborns by GA are presented in Table 2 and those of female newborns in Table 3. Smoothed new Korean reference curves for birth weight of the 3 th, 10th, 25th, 50th, 75th, 90th, and 97th percentiles for male and female neonates are shown in Fig. 1. The LMS parameters for the curves are presented in Table 4. SGA is defined as birth weight $<10$ th percentile for GA and LGA as birth weight $>90$ th percentile for GA.

\section{Comparison of new Korean reference curves for birth weight with the 2010 US intrauterine growth curves and Lubchenco curve}

The new Korean reference curves for birth weight were plotted with the 2010 US intrauterine growth curves for comparison (Fig. 2A, B). Generally, the new Korean curves were similar to the 2010 US intrauterine growth curves until GA 36 weeks in both sexes. However, the Korean curves had lower average birth weight after GA 37 weeks. The 50th and 90th birth weight of Korean was lower after GA 37 weeks but 10th birth weight was similar to that of the US in both sexes.

The new Korean reference curves for birth weight were also plotted with the Lubchenco curves (Fig. 2C, D). Generally, the 90th percentile birth weight of Korean curves was lower than that of Lubchenco's in GA less than 36 weeks. However, the 90th

Table 2. Mean and percentile birth weight by gestational age in male Korean neonates $(n=1,159,070)$

\begin{tabular}{|c|c|c|c|c|c|c|c|c|c|c|}
\hline \multirow{2}{*}{$\begin{array}{l}G A^{a)} \\
(w k)\end{array}$} & \multirow{2}{*}{ No. } & \multicolumn{2}{|c|}{ Birth weight (g) } & \multicolumn{7}{|c|}{ Percentiles } \\
\hline & & Mean & SD & $3 r d$ & 10th & 25th & 50th & 75th & 90th & 97th \\
\hline 23 & 105 & 620 & 80 & 480 & 510 & 570 & 630 & 680 & 720 & 760 \\
\hline 24 & 197 & 730 & 100 & 520 & 610 & 680 & 740 & 800 & 860 & 920 \\
\hline 25 & 298 & 820 & 130 & 520 & 640 & 750 & 830 & 900 & 970 & 1,040 \\
\hline 26 & 416 & 940 & 140 & 600 & 750 & 860 & 950 & 1,030 & 1,100 & 1,190 \\
\hline 27 & 548 & 1,060 & 170 & 690 & 830 & 970 & 1,070 & 1,180 & 1,270 & 1,370 \\
\hline 28 & 745 & 1,180 & 210 & 710 & 900 & 1,060 & 1,210 & 1,320 & 1,420 & 1,530 \\
\hline 29 & 891 & 1,330 & 250 & 760 & 1,000 & 1,200 & 1,360 & 1,490 & 1,610 & 1,750 \\
\hline 30 & 1,130 & 1,510 & 280 & 940 & 1,130 & 1,350 & 1,530 & 1,680 & 1,810 & 2,030 \\
\hline 31 & 1,480 & 1,690 & 290 & 1,080 & 1,280 & 1,530 & 1,715 & 1,870 & 2,030 & 2,210 \\
\hline 32 & 2,175 & 1,900 & 320 & 1,240 & 1,490 & 1,730 & 1,920 & 2,100 & 2,270 & 2,520 \\
\hline 33 & 3,205 & 2,120 & 350 & 1,380 & 1,680 & 1,930 & 2,130 & 2,340 & 2,530 & 2,820 \\
\hline 34 & 6,155 & 2,350 & 360 & 1,600 & 1,910 & 2,140 & 2,360 & 2,570 & 2,800 & 3,100 \\
\hline 35 & 11,175 & 2,600 & 360 & 1,870 & 2,150 & 2,380 & 2,600 & 2,820 & 3,060 & 3,330 \\
\hline 36 & 27,092 & 2,830 & 370 & 2,100 & 2,380 & 2,600 & 2,820 & 3,060 & 3,300 & 3,600 \\
\hline 37 & 96,514 & 3,080 & 370 & 2,380 & 2,620 & 2,840 & 3,080 & 3,320 & 3,560 & 3,820 \\
\hline 38 & 295,872 & 3,250 & 360 & 2,590 & 2,800 & 3,000 & 3,230 & 3,480 & 3,700 & 3,960 \\
\hline 39 & 341,418 & 3,340 & 360 & 2,700 & 2,900 & 3,100 & 3,320 & 3,580 & 3,800 & 4,040 \\
\hline 40 & 294,588 & 3,440 & 360 & 2,800 & 3,000 & 3,200 & 3,420 & 3,680 & 3,900 & 4,140 \\
\hline 41 & 71,644 & 3,500 & 360 & 2,850 & 3,040 & 3,250 & 3,500 & 3,730 & 3,960 & 4,200 \\
\hline 42 & 3,212 & 3,510 & 380 & 2,840 & 3,010 & 3,250 & 3,500 & 3,750 & 4,000 & 4,270 \\
\hline 43 & 210 & 3,400 & 430 & 2,610 & 2,900 & 3,100 & 3,395 & 3,720 & 3,900 & 4,320 \\
\hline
\end{tabular}

GA, gestational age; SD, standard deviation.

${ }^{a)} \mathrm{GA} 36$ weeks represent 36 weeks +0 day to +6 days. 
percentile of GA over 37 weeks had birth weight slightly higher than that of Lubchenco's. The 50th birth weight of Korean population was lower until 30 weeks and higher after 37 weeks. The 10th birth weight cutoff of Korean curves was higher than the Lubchenco curves after 32 weeks in both sexes. Thus, the number of SGA in Korean population according to Lubchenco was smaller than that according to the new Korean reference cutoff. The prevalence of SGA according to $<10$ th percentile of



the Lubchenco curves was 1.92\% (male, 1.90\%; female, 1.95\%), while the prevalence of SGA according to $\leq 3 \mathrm{rd}$ percentile and $<10$ th percentile of the new Korean reference curves were $2.88 \%$ (male, 2.90\%; female, 2.86\%) and 9.56\% (male, 9.43\%; female, $9.70 \%$ ), respectively. The prevalence of LGA (>90th percentile) according to the Lubchenco and the new Korean reference curves were $11.31 \%$ (male, $11.11 \%$; female, $11.53 \%$ ) and $9.79 \%$ (male, 9.76\%; female, 9.82\%), respectively.

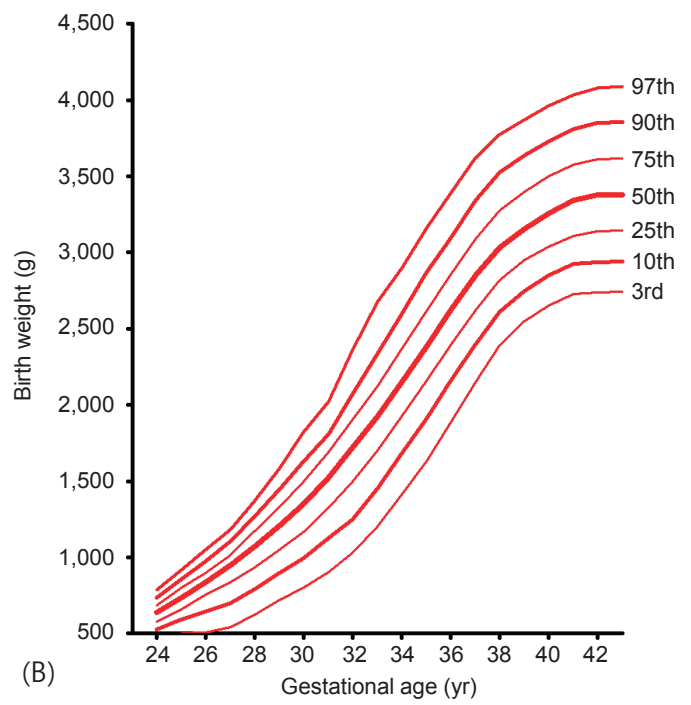

Fig. 1. The new Korean birth weight curves for male (A) and female (B) newborns.

Table 3. Mean and percentile birth weight by gestational age in female Korean neonates $(n=1,090,734)$

\begin{tabular}{|c|c|c|c|c|c|c|c|c|c|c|}
\hline \multirow{2}{*}{$\begin{array}{l}G A^{\text {a) }} \\
(w k) \\
\end{array}$} & \multirow{2}{*}{ No. } & \multicolumn{2}{|c|}{ Birth weight (g) } & \multicolumn{7}{|c|}{ Percentiles } \\
\hline & & Mean & SD & $3 r d$ & 10th & 25th & 50th & 75th & 90th & 97th \\
\hline 23 & 74 & 580 & 80 & 420 & 490 & 540 & 590 & 640 & 670 & 720 \\
\hline 24 & 191 & 680 & 90 & 470 & 570 & 620 & 690 & 740 & 800 & 850 \\
\hline 25 & 311 & 770 & 120 & 490 & 620 & 700 & 780 & 740 & 920 & 990 \\
\hline 26 & 397 & 880 & 150 & 510 & 660 & 810 & 900 & 980 & 1030 & 1110 \\
\hline 27 & 512 & 970 & 180 & 570 & 720 & 865 & 1000 & 1100 & 1180 & 1260 \\
\hline 28 & 682 & 1,120 & 200 & 720 & 840 & 1000 & 1140 & 1250 & 1360 & 1480 \\
\hline 29 & 723 & 1,260 & 240 & 820 & 920 & 1,100 & 1,280 & 1,410 & 1,540 & 1,690 \\
\hline 30 & 946 & 1,410 & 290 & 840 & 1,040 & 1,240 & 1,420 & 1,590 & 1,720 & 1,960 \\
\hline 31 & 1,176 & 1,590 & 300 & 970 & 1,160 & 1,410 & 1,630 & 1,790 & 1,910 & 2,070 \\
\hline 32 & 1,693 & 1,810 & 370 & 1,090 & 1,330 & 1,590 & 1,810 & 2,020 & 2,230 & 2,650 \\
\hline 33 & 2,374 & 2,020 & 350 & 1,320 & 1,580 & 1,810 & 2,040 & 2,230 & 2,440 & 2,700 \\
\hline 34 & 4,622 & 2,270 & 390 & 1,500 & 1,780 & 2,040 & 2,260 & 2,500 & 2,750 & 3,060 \\
\hline 35 & 8,367 & 2,500 & 380 & 1,760 & 2,040 & 2,280 & 2,500 & 2,730 & 2,970 & 3,260 \\
\hline 36 & 20,926 & 2,740 & 380 & 2,010 & 2,280 & 2,500 & 2,740 & 2,980 & 3,220 & 3,520 \\
\hline 37 & 77,453 & 2,980 & 370 & 2,290 & 2,520 & 2,740 & 2,960 & 3,200 & 3,460 & 3,720 \\
\hline 38 & 255,375 & 3,130 & 350 & 2,500 & 2,700 & 2,900 & 3,110 & 3,350 & 3,590 & 3,830 \\
\hline 39 & 318,377 & 3,220 & 350 & 2,600 & 2,800 & 3,000 & 3,200 & 3,450 & 3,680 & 3,910 \\
\hline 40 & 309,996 & 3,320 & 350 & 2,700 & 2,900 & 3,080 & 3,300 & 3,550 & 3,780 & 4,010 \\
\hline 41 & 8,296 & 3,380 & 350 & 2,760 & 2,950 & 3,140 & 3,380 & 3,600 & 3,840 & 4,060 \\
\hline 42 & 3,611 & 3,390 & 370 & 2,720 & 2,920 & 3,140 & 3,380 & 3,620 & 3,860 & 4,100 \\
\hline 43 & 232 & 3,350 & 350 & 2,700 & 2,850 & 3,105 & 3,340 & 3,600 & 3,800 & 3,950 \\
\hline
\end{tabular}

$\mathrm{GA}$, gestational age; $\mathrm{SD}$, standard deviation.

${ }^{a} G A 36$ weeks represent 36 weeks +0 day to +6 days. 


\section{Discussion}

In this study, we developed the new Korean reference curves for birth weight by GA and sex based on the data of contemporary Korean infants. This new Korean birth weight data set and growth curves might be useful not only in assessing short-term health risks of SGA infants in neonatal intensivecare units but also in assessing long-term health risks such as short stature in childhood and metabolic risk in adulthood among children born SGA or LGA. Furthermore, possible misclassification of SGA infants using the Lubchenco curves, which was based on the old data of the US neonates and has commonly been used in Korea, supports the need for updated and Korean specific reference curves for birth weight.

\section{The need for birth weight reference by GA and definition of SGA}

Contemporary ethnicity specific birth weight references are needed to identify SGA infants who might suffer from acute and chronic consequences ${ }^{9}$. Some of SGA neonates are born following IUGR. Suboptimal fetal growth occurring in IUGR fetuses is an important cause of perinatal mortality and morbidity ${ }^{2,3)}$. They suffer from hypoglycemia, anemia, hypothermia, respiratory distress, necrotizing enterocolitis, and retinopathy of prematurity, which contribute to perinatal morbidity. Furthermore, SGA children have significantly increased risks of obesity, hypertension, dyslipidemia,
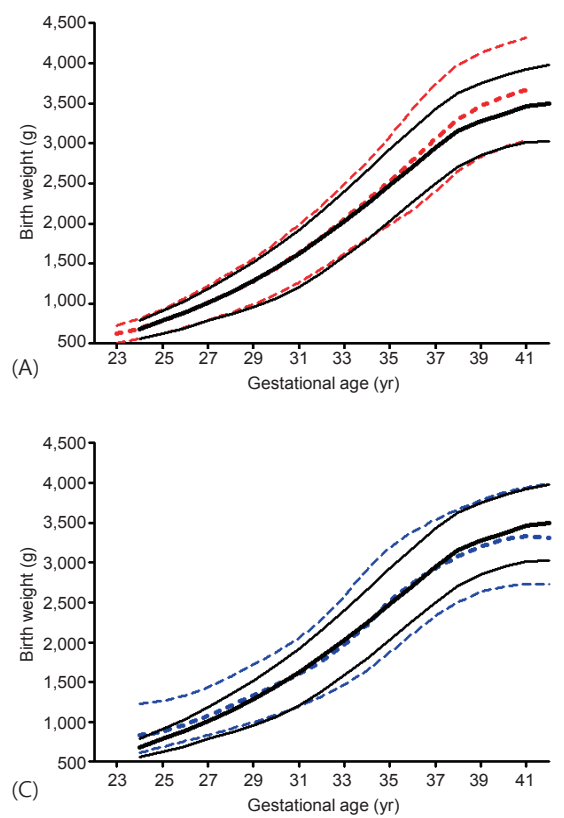

insulin resistance, type 2 diabetes mellitus, and CVD from children to adulthood ${ }^{3,8}$. In children and adolescents, they present endocrine sequelae, such as short stature, which persists into adults, premature adrenarche, and polycystic

Table 4. The new Korean birth weight curves $L, M$, and $S$ parameters

\begin{tabular}{|c|c|c|c|c|c|c|}
\hline \multirow{2}{*}{$\begin{array}{l}\mathrm{GA}^{\mathrm{a})} \\
(\mathrm{wk}) \\
\end{array}$} & \multicolumn{3}{|c|}{ Male growth curves } & \multicolumn{3}{|c|}{ Female growth curves } \\
\hline & L & $M$ & $S$ & L & M & $S$ \\
\hline 23 & -0.30 & 630 & 12.86 & -0.41 & 590 & 13.22 \\
\hline 24 & -0.26 & 740 & 13.26 & -0.06 & 690 & 13.90 \\
\hline 25 & -0.45 & 830 & 15.77 & -0.34 & 780 & 15.74 \\
\hline 26 & -0.52 & 950 & 15.09 & -0.72 & 900 & 16.83 \\
\hline 27 & -0.38 & 1,070 & 16.17 & -0.59 & 1,000 & 18.48 \\
\hline 28 & -0.44 & 1,210 & 18.03 & -0.17 & 1,140 & 18.22 \\
\hline 29 & -0.46 & 1,360 & 18.82 & -0.06 & 1,280 & 18.84 \\
\hline 30 & -0.13 & 1,530 & 18.51 & 0.12 & 1,420 & 20.38 \\
\hline 31 & -0.23 & 1,720 & 17.09 & -0.27 & 1,630 & 18.74 \\
\hline 32 & -0.14 & 1,920 & 16.70 & 0.24 & 1,810 & 20.60 \\
\hline 33 & -0.13 & 2,130 & 16.43 & -0.06 & 2,040 & 17.08 \\
\hline 34 & -0.01 & 2,360 & 15.40 & 0.07 & 2,260 & 16.99 \\
\hline 35 & 0.04 & 2,600 & 14.04 & 0.03 & 2,500 & 14.99 \\
\hline 36 & 0.07 & 2,820 & 13.23 & 0.12 & 2,740 & 13.99 \\
\hline 37 & 0.08 & 3,080 & 12.11 & 0.15 & 2,960 & 12.45 \\
\hline 38 & 0.13 & 3,230 & 11.12 & 0.16 & 3,110 & 11.18 \\
\hline 39 & 0.15 & 3,320 & 10.68 & 0.17 & 3,200 & 10.81 \\
\hline 40 & 0.14 & 3,420 & 10.47 & 0.17 & 3,300 & 10.56 \\
\hline 41 & 0.16 & 3,500 & 10.27 & 0.16 & 3,380 & 10.23 \\
\hline 42 & 0.22 & 3,500 & 10.79 & 0.13 & 3,380 & 10.83 \\
\hline 43 & 0.05 & 3,400 & 12.73 & -0.14 & 3,340 & 10.52 \\
\hline
\end{tabular}

GA, gestational age; LMS, Lambda Mu Sigma.

${ }^{\text {a) }} \mathrm{GA} 36$ weeks represent 36 weeks +0 day to +6 days.
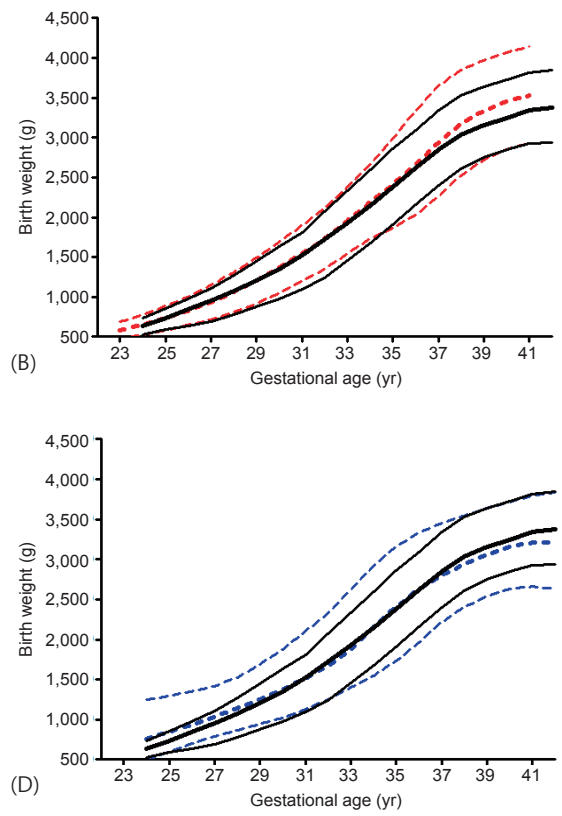

Fig. 2. The new Korean birth weight curves (black solid line) compared with the 2010 United States intrauterine growth curves (red dashed line) for male (A) and female (B) newborns/Lubchenco curves (blue dashed line) for male (C) and female (D) newborns. The line represents 10th, 50th, and 90th birth percentile, respectively. 
ovarian syndrome $e^{4-7)}$. These sequelae can be prevented or managed if diagnosed early and appropriately. For example, growth hormone $(\mathrm{GH})$ treatment for children without catch up is considered a standard practice ${ }^{19-21)}$. Approximately 13\% of children born SGA without catch up remain short and constitute a significant proportion of adults with short stature ${ }^{22)}$. Many studies have shown that adult height is increased by GH therapy in these children ${ }^{19,21)}$. Short-term GH treatment also reduces body fat while promoting lean body mass, which might reduce cardio-metabolic risk in SGA children ${ }^{23)}$. Furthermore, a study in Sweden reported GH therapy was associated with a significant and cost-effective improvement in health and quality of life ${ }^{24)}$. Although data concerning the safety of GH therapy in SGA are limited, the safety profile for idiopathic short stature indicated relatively low rates of adverse events ${ }^{25}$. Thus, U.S. Food and Drug Administration and the European Medicines Agency approved GH treatment for short stature in children born SGA. The other examples are premature adrenarche and polycystic ovarian syndrome in girls born SGA. Some hypothesized that adipose tissue expandability from insulin resistance and dyslipidemia in SGA girls leads to premature pubarche, followed by polycystic ovarian syndrome (PCOS) in adolescents ${ }^{26)}$.

A controlled trial reported the results of using metformin in girls born SGA with premature pubarche ${ }^{7}$. Girls receiving early metformin showed low visceral fat, reduced androgen, taller height, and low PCOS prevalence. The authors concluded that early metformin prevented or delayed the manifestations of hyperandrogenism and that the timing of treatment might be important. Therefore, it is important to define SGA not only to reduce perinatal morbidity but also to manage short stature, premature adrenarche and polycystic ovarian syndrome in children and adolescents.

\section{Comparison of the new Korean birth weight curves with other curves including the Lubchenco curves}

It is well known that there is racial and ethnic difference in birth weight ${ }^{27-29)}$. Further, significant interactions were found between race and maternal variables, such as education, marital status, birthplace, and the month when antenatal care began. Thus, ethnicity and sex specific reference for birth weight must be made. Compared to the 2010 US intrauterine growth data ${ }^{10)}$, new Korean references for birth weight values are slightly higher than those of the US for infants with GA less than 36 weeks. That's because our reference of 36 weeks represent 36 weeks plus 0 to 6 days, while the US expected GA was defined as the closest week (GA 36 weeks; 35 weeks +4 day to 36 weeks +3 day) by obstetrical history, prenatal ultrasound, and postnatal physical examinations. Thus, we made LMS curves adjusted by GA. The New Korean reference curves were almost the same as the 2010 US intrauterine growth curves, except that the 50th percentile value of GA over 38 weeks and 90th percentile value of GA over 35 weeks were lower than US references. These might be racial difference between White and Korean populations. White infants are known to be heavier, taller, and have a larger heads than Asians ${ }^{27,29)}$

When compared with New Japanese neonatal anthropometric charts for $\mathrm{GA}^{15)}$, the new Korean reference values were slight lower in preterm but slightly higher in term. It is well known that different inclusion criteria and the heterogeneity of methods used to trace neonatal growth charts result in wide differences in the cutoff values. The main reason for these differences is that the new Japanese charts were made based on the data of subjects born only by vaginal delivery and divided by primiparity/multiparity. About $40 \%$ of the subjects in the new Korean references might be born by cesarean section ${ }^{30)}$. Neonates born by cesarean section had lower birth weight in preterm $^{31)}$. Thus, the distribution of 10th percentile curves was skewed toward lower birth weights during the preterm period births delivered by cesarean section. The term baby's higher weight in Korean population might be an ethnic difference. The height and weight of Korean mother might be taller and heavier. The birth weight and length was also known to be related with mother's weight and height ${ }^{32)}$. In previous Korean birth weight data divided by primiparity/multiparity also showed higher weight in term than that of Japanese population ${ }^{33)}$.

When compared with the Lubchenco's data, the 90th percentile birth weight cutoff of Korean curves was lower than that of Lubchenco's and the 10th birth weight cutoff of Korean curves was higher after 32 weeks than the Lubchenco curves. Lubchenco curves were made from White neonates in 1948 to $1963^{34)}$. The differences of 90 th percentile might be the racial difference between White and Asian. White infants are heavier and longer even in preterm. In 1950s, IUGR fetuses may have died in utero, delivered severely macerated, and not included in that database. Furthermore, recent advancement of highrisk pregnancies care resulted in extended periods of growth restriction in Korea. The differences of 10th percentile birth weight cutoff might be also explained in part by advanced highrisk pregnancies care and neonatal care nowadays ${ }^{10)}$. Another component is the nutritional state of Korean mothers, which can be better than those of Colorado. Thus the Korean 10th percentile birth weight cutoffs are shifted up and as a result, the percentage of both LGA (especially GA under 36 weeks) and SGA can be underestimated by the Lubchenco curves compared with the new Korean birth weight curves. There are some limitations in the present study. First and, the most important limitation of this reference, like other population-based studies, is its cross-sectional nature based on birth certificates. Rather than longitudinal measurements of the same fetus over the course of gestation, the references are based on the birth weights of different infants born at different GAs $9,{ }^{35}$. Thus, preterm infants are somewhat smaller than fetuses of the same GA who remain in utero ${ }^{36)}$. Second, we were unable to make references of length for GA, which is also important for determining SGA, because information about birth length was not included in the KOSIS data. The birth length for GA might be different between the 2010 US intrauterine growth data and the 2014 Japanese neonatal anthropometric data. Further research is needed in Korean as well. Third, we did not make separate charts for 
neonates from primiparous and multiparous mothers. It is well known that birth weights of infants of multiparous mothers are heavier than those of primiparous mothers by 20-50 $\mathrm{g}^{33)}$. However, most of the subjects in this study were 1st baby as birth rate per woman is 1.14 in Korean. Finally, the new Korean references of birth weight were based on round off GA and the curves were made on nearest GA.

In conclusion, we calculated the means and percentiles of birth weight in Korean neonates by GA on the basis of KOSIS data. We created new sex specific reference curves for birth weight by GA using the data of almost all contemporary Korean neonates. We also created new cutoffs of SGA and LGA. As some SGA and LGA infants had short-term and long-term health risks, these data and curves provide useful information not only for endocrinologists but also for other specialists, including neonatologists in Korea for planning research or targeting to prevent metabolic diseases, such as obesity, diabetes, and CVD.

\section{Conflict of interest}

No potential conflict of interest relevant to this article was reported.

\section{References}

1. Carlo WA. Prematurity and intrauterine growth restriction. In: Kliegman RM, Stanton BF, St. Geme JW, Schor NF, Behrman RE. Nelson textbook of pediatrics. 19th ed. Philadelphia, PA: Elsevier Saunders, 2011:555-64.

2. Bae CW, Kim MH, Chun CS, Lee C, Moon SJ, Yoo BH, et al. Neonatal Statistics of Korea in 1996: collective results of live-births, neonatal mortality, and incidence of dischage against medical advice at 64 hospitals. J Korean Soc Neonatol 1997;4:153-69.

3. Chernausek SD. Update: consequences of abnormal fetal growth. J Clin Endocrinol Metab 2012;97:689-95.

4. Itabashi K, Mishina J, Tada H, Sakurai M, Nanri Y, Hirohata Y. Longitudinal follow-up of height up to five years of age in infants born preterm small for gestational age; comparison to full-term small for gestational age infants. Early Hum Dev 2007;83:327-33.

5. Karlberg J, Albertsson-Wikland K. Growth in full-term small-for-gestational-age infants: from birth to final height. Pediatr Res 1995;38:733-9.

6. Hernandez MI, Mericq V. Impact of being born small for gestational age on onset and progression of puberty. Best Pract Res Clin Endocrinol Metab 2008;22:463-76.

7. Ibanez L, Lopez-Bermejo A, Diaz M, Marcos MV, de Zegher F. Early metformin therapy (age 8-12 years) in girls with precocious pubarche to reduce hirsutism, androgen excess, and oligomenorrhea in adolescence. J Clin Endocrinol Metab 2011;96:E1262-7.

8. Barker DJ. Outcome of low birthweight. Horm Res 1994;42: 223-30.
9. Goldenberg RL, Cutter GR, Hoffman HJ, Foster JM, Nelson KG, Hauth JC. Intrauterine growth retardation: standards for diagnosis. Am J Obstet Gynecol 1989;161:271-7.

10. Olsen IE, Groveman SA, Lawson ML, Clark RH, Zemel BS. New intrauterine growth curves based on United States data. Pediatrics 2010;125:e214-24.

11. Cole TJ, Williams AF, Wright CM; RCPCH Growth Chart Expert Group. Revised birth centiles for weight, length and head circumference in the UK-WHO growth charts. Ann Hum Biol 2011;38:7-11.

12. Salihoglu O, Karatekin G, Uslu S, Can E, Baksu B, Nuhoglu A. New intrauterine growth percentiles: a hospital-based study in Istanbul, Turkey. J Pak Med Assoc 2012;62:1070-4.

13. Sankilampi U, Hannila ML, Saari A, Gissler M, Dunkel L. New population-based references for birth weight, length, and head circumference in singletons and twins from 23 to 43 gestation weeks. Ann Med 2013;45:446-54.

14. Kumar VS, Jeyaseelan L, Sebastian T, Regi A, Mathew J, Jose R. New birth weight reference standards customised to birth order and sex of babies from South India. BMC Pregnancy Childbirth 2013;13:38.

15. Itabashi K, Miura F, Uehara R, Nakamura Y. New Japanese neonatal anthropometric charts for gestational age at birth. Pediatr Int 2014 Mar 12 [Epub]. http://dx.doi.org/10.1111/ ped.12331.

16. Korean Statistical Information Service [Internet]. Daejeon: KOSIS; [cited 2014 Aug 20]. Available from: http://kosis.kr/.

17. Tukey JW. Exploratory data analysis. Don Mills, CA: Addison- Wesley, 1977.

18. Cole TJ, Green PJ. Smoothing reference centile curves: the LMS method and penalized likelihood. Stat Med 1992;11: 1305-19.

19. Clayton PE, Cianfarani S, Czernichow P, Johannsson G, Rapaport R, Rogol A. Management of the child born small for gestational age through to adulthood: a consensus statement of the International Societies of Pediatric Endocrinology and the Growth Hormone Research Society. J Clin Endocrinol Metab 2007;92:804-10.

20. Boguszewski MC, Mericq V, Bergada I, Damiani D, Belgorosky A, Gunczler P, et al. Latin American consensus: children born small for gestational age. BMC Pediatr 2011;11:66.

21. Ranke MB, Lindberg A; KIGS International Board. Prediction models for short children born small for gestational age (SGA) covering the total growth phase. Analyses based on data from KIGS (Pfizer International Growth Database). BMC Med Inform Decis Mak 2011;11:38.

22. Albertsson-Wikland K, Karlberg J. Natural growth in children born small for gestational age with and without catch-up growth. Acta Paediatr Suppl 1994;399:64-70.

23. Ibanez L, Lopez-Bermejo A, Diaz M, Jaramillo A, Marin S, de Zegher F. Growth hormone therapy in short children born small for gestational age: effects on abdominal fat partitioning and circulating follistatin and high-molecular- 
weight adiponectin. J Clin Endocrinol Metab 2010;95: 2234-9.

24. Christensen T, Fidler C, Bentley A, Djurhuus C. The costeffectiveness of somatropin treatment for short children born small for gestational age (SGA) and children with growth hormone deficiency (GHD) in Sweden. J Med Econ 2010;13:168-78.

25. Bell J, Parker KL, Swinford RD, Hoffman AR, Maneatis T, Lippe B. Long-term safety of recombinant human growth hormone in children. J Clin Endocrinol Metab 2010;95: 167-77.

26. de Zegher F, Lopez-Bermejo A, Ibanez L. Adipose tissue expandability and the early origins of PCOS. Trends Endocrinol Metab 2009;20:418-23.

27. Wang X, Guyer B, Paige DM. Differences in gestational agespecific birthweight among Chinese, Japanese and white Americans. Int J Epidemiol 1994;23:119-28.

28. Shiono PH, Rauh VA, Park M, Lederman SA, Zuskar D Ethnic differences in birthweight: the role of lifestyle and other factors. Am J Public Health 1997;87:787-93.

29. Madan A, Holland S, Humbert JE, Benitz WE. Racial differences in birth weight of term infants in a northern
California population. J Perinatol 2002;22:230-5.

30. Lee SI, Khang YH, Lee MS. Women's attitudes toward mode of delivery in South Korea: a society with high cesarean section rates. Birth 2004;31:108-16.

31. Uehara R, Miura F, Itabashi K, Fujimura M, Nakamura Y. Distribution of birth weight for gestational age in Japanese infants delivered by cesarean section. J Epidemiol 2011;21: 217-22.

32. Maternal anthropometry and pregnancy outcomes. A WHO Collaborative Study. Bull World Health Organ 1995;73 Suppl: 1-98.

33. Lee JJ. Birth weight for gestational age patterns by sex, plurality, and parity in Korean population. Korean J Pediatr 2007; 50:732-9.

34. Lubchenco LO, Hansman C, Dressler M, Boyd E. Intrauterine growth as estimated from liveborn birth-weight data at 24 to 42 weeks of gestation. Pediatrics 1963;32:793-800.

35. Wilcox AJ. Birth weight, gestation, and the fetal growth curve. Am J Obstet Gynecol 1981;139:863-7.

36. Hediger ML, Scholl TO, Schall JI, Miller LW, Fischer RL. Fetal growth and the etiology of preterm delivery. Obstet Gynecol 1995;85:175-82. 